Scientific Journal of Hamadan Nursing \& Midwifery Faculty - ISSN 2008-2819

\title{
The Effect of Inhalation Aromatherapy with Lavender Essence on Pain Intensity and Anxiety in Burn Patients: A Clinical Randomized Trial
}

\author{
Azim Azizi' ${ }^{1}$ Khodayar Oshvandi², Maryam Farhadian³ ${ }^{3}$, Atefeh Lashani*4 \\ 1. Assistant Professor, Department of Medical Surgical, Malayer School of Nursing, Hamadan University of Medical \\ Sciences, Hamadan, Iran \\ 2. Associate Professor, Department of Medical Surgical, Faculty of Nursing and Midwifery, Hamadan University of \\ Medical Sciences, Hamadan, Iran \\ 3. Associate Professor, Department of Biostatistics, School of Public Health, Hamadan University of Medical Sciences \\ Hamadan, Iran \\ 4. MSc., Student Research Committee, Faculty of Nursing and Midwifery, Hamadan University of Medical Sciences, \\ Hamadan, Iran
}

\section{Article Info \\ Received: 2018/08/9; \\ Accepted: 2018/09/1; \\ Published Online: 2019/01/21 \\ DOI: \\ $\underline{10.30699 / \text { sjhnmf.26.6.416 }}$}

Original Article

Use your device to scan and read the article online

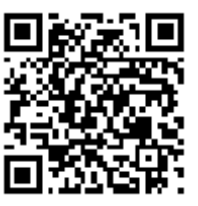

Corresponding Information:

\section{ABSTRACT}

Introduction: Pain is one of the common problems in burn patients. Inhalation aromatherapy is one of the nurses' methods for pain management. However, there is not much information available about the effect of these methods on pain in burn patients. This study aimed to evaluate the effect of inhalation aromatherapy with Lavender essence on the pain intensity in burn patients.

Methods: The present study was a single-blind, three-group clinical trial. The research population consisted of patients with burns in one of Hamadan hospitals. One hundred and twenty patients were selected using convenience sampling and randomly assigned into three groups of lavender, placebo and control groups. The intervention included inhalation of 10 drops of lavender extract in the examiation group, 10 drops of distilled water in the placebo group, for one hour before wound dressing, and routine care in the control group. Pain in patients was evaluated before, immediately after intervention (before dressing), and after dressing using a visual analogue scale. The data were analyzed using SPSS 21 and one-way and repeated measures ANOVA with significant level of $P<0.05$.

Results: Demographic variables were similar in all three groups. There was a significant difference between the mean pain intensity in the groups after intervention $(P<0.05)$, which was significant between the lavender group with placebo and control group $(P<0.05)$. There was not a statistically significant difference between the control and placebo groups $(P=0 / 443)$.

Conclusion: The use of lavender aroma can reduce short-term pain of burn patients. Therefore, the use of lavender aroma is recommended in short term pain by medical staff and nurses.

Keywords: Complementary medicine, Aroma therapy, Lavender, Pain, Intensive Care Unit, Burn patients
Atefeh Lashani MSc., Student Research Committee, School of Nursing and Midwifery, Hamadan University of Medical Sciences, Hamadan, Iran. Emai: lashani.uni@gmail.com

Copyright $($ ) 2019, Sci J Hamadan Nurs Midwifery Fac. This is an open-access article distributed under the terms of the Creative Commons Attribution-noncommercial 4.0 International License which permits copy and redistribute the material just in noncommercial usages, provided the original work is properly cited.

\section{How to Cite This Article:}

Azizi A, Oshvandi K, Farhahian M, Lashani A. The Effect of Inhalation Aromatherapy with Lavender Essence on Pain Intensity and Anxiety in Burn Patients: A Clinical Randomized Trial. Sci J Hamadan Nurs Midwifery Fac. 2019; 26 (6) :416-427 


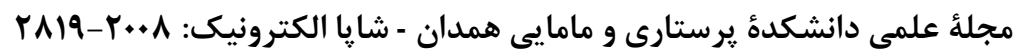

$$
\text { مقاله يثروهشى }
$$

اثربخشى رايحهدرمانى استنشاقى با اسانس اسطوخودوس بر شدت درد بيماران سوختكى؛

$$
\text { مطالعة كار آزمايى بالينى }
$$

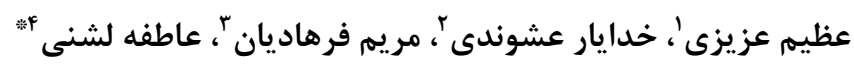

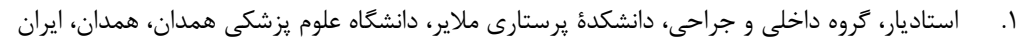

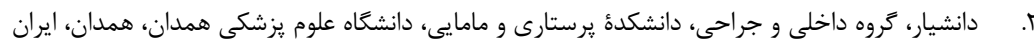

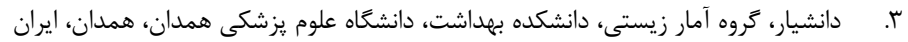

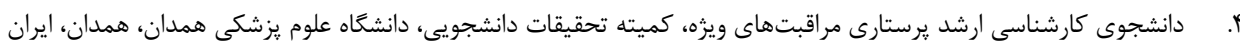

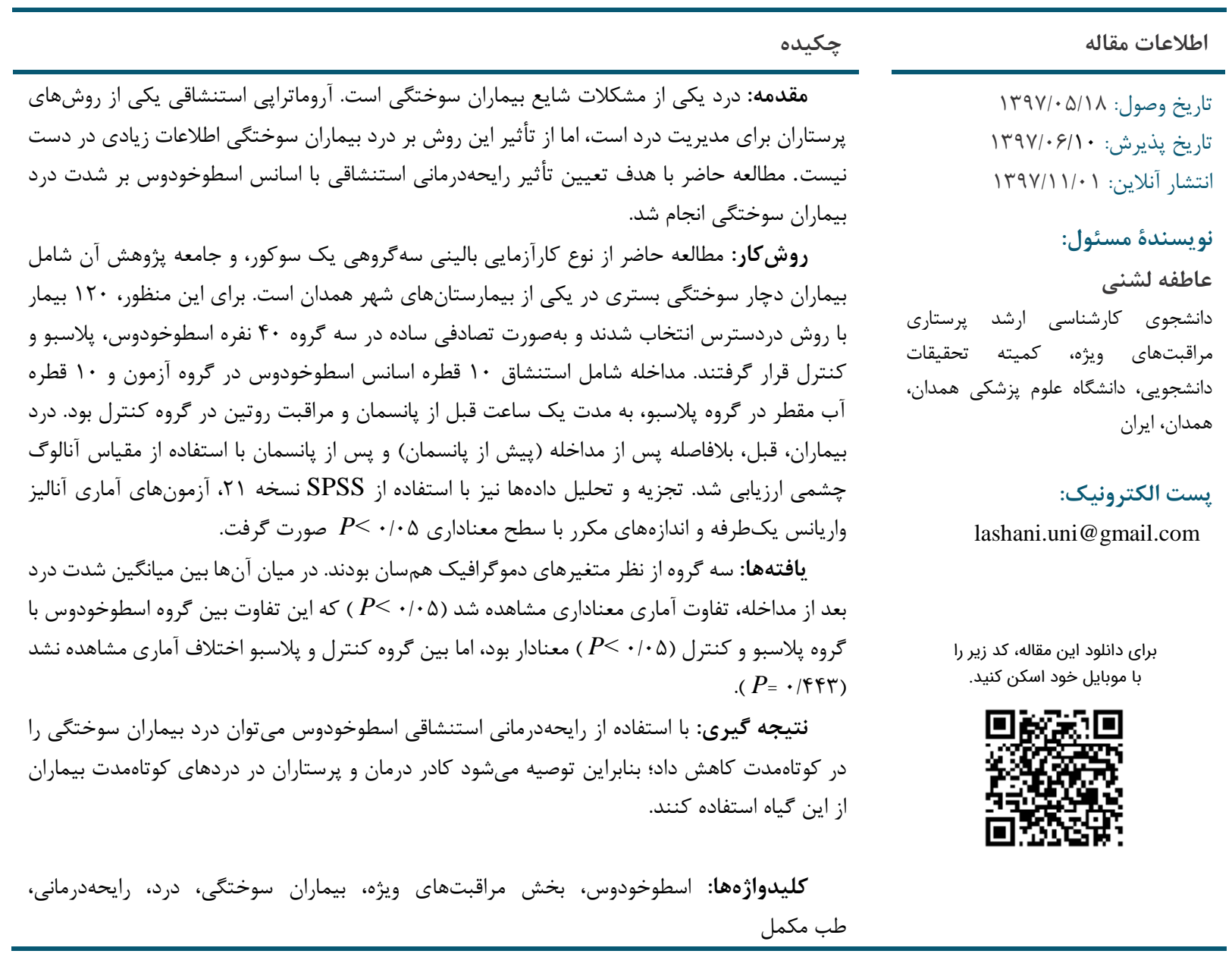

سوختگى مىشوند كه از اين تعداد •r هزار نفر بسترى

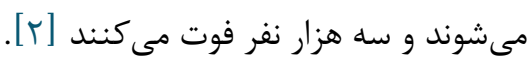
آسيب سوختگى و اقدامات درمانى سبب بروز شديدترين

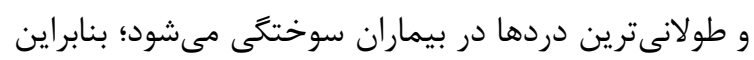

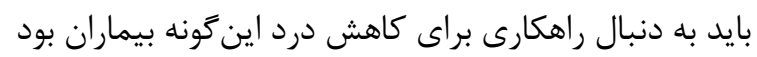

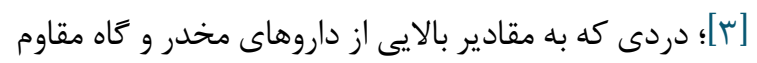

سوختگى وضعيت اسفناكى است كه بيشتر در كشورهاى

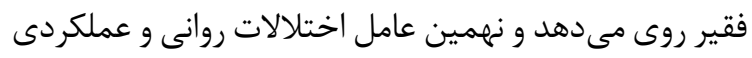
نيز در ايران بلشمار مى آيد. به كزارش مركز تحميل تحقيقات سوختگى دانشگاه ايران، آمار بيماران سوختخى دئ در كشور

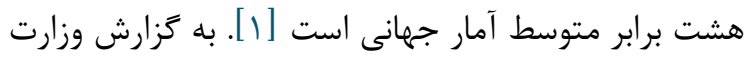

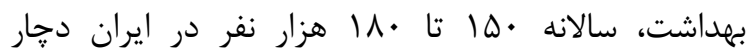


سيستم عصبى تمامى سيستمهاى بدن را درگير مىكند و

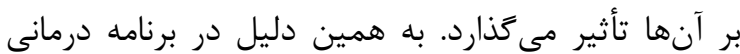
كنترل درد مدنظر قرار دارد [1 I إن]. در مطالعات اخير پييامدهاى رايحهدرمانى در كاهش درد درد بررسى شده است. در بيشتر يزوهشها نيز اثر مثبت

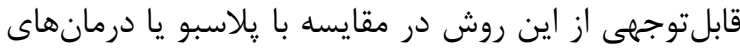

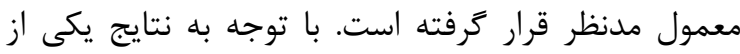
مطالعات، تحريك بويايى با استفاده از رايحهدرمانى مىتواند به كاهش فورى درد و تغييرات فيزيولوزيكى از قبيل

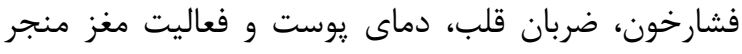
شود [بآ]. در اين ميان، اسانس اسطوخودوس در رايحه

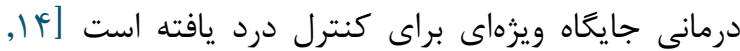

بهنظر مىرسد اسطوخودوس پِيامدهاى ضد استرسى، آرامبخشى، ضد دردى، آنتىهيستامينى و تسكيندهنده

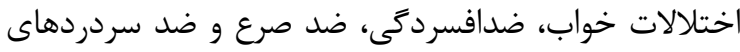

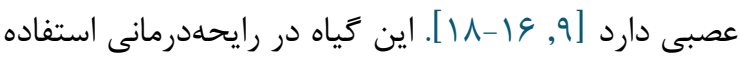
مىشود و بهكمك آن مىتوان آثار آرامبخشى، ضد درد و ضد دارد انقباضى را از طريق سيستم نورولوزيك نمايان كرد [19 19].

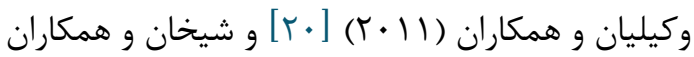

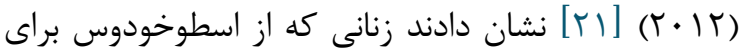
كاهش درد إيزياتومى بهره بردند، از مسكن كمترى استفاده

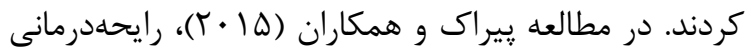

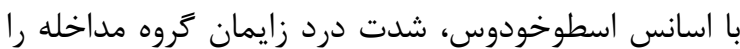
در مقايسه با كروه كنترل كاهش داد [ [r/]. در مطالعه لاماده

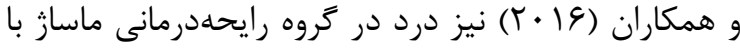
اسانس اسطوخودوس از كروه ماساز بدون رايحهدرمانى كمتر

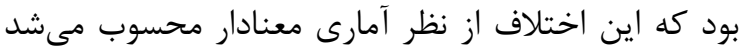

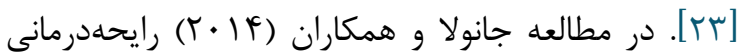

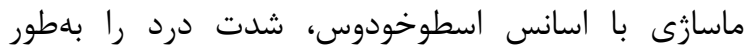
معنادارى كاهش داد [ץT]. در مطالعه سيدى و همكاران

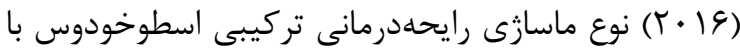

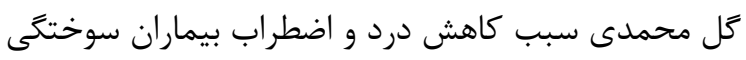

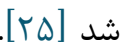
مطالعه حاضر با هدف ”بررسى تأثير رايحهدرمانى استنشاقى با اسانس اسطوخودوس بر شدت دردي درد بيماران

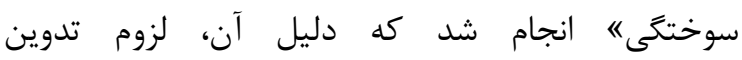
دستورالعملهايى براى استفاده از رايحههاى انتخابى و مؤثر
به آن نيازمند است [Y]]. نتايج مطالعهاى در برزيل (Y) (Y) نشان مىدهد سوختكى سبب تخريب شديد بافتهاى بدن

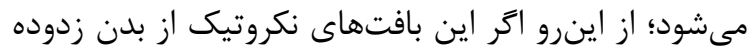

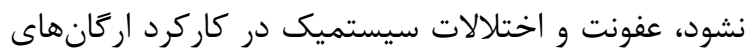
حياتى بلوجود مى آيد. يكى از عواملى كه مانع از بين بردن

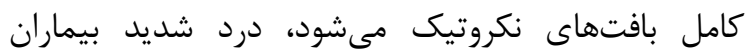

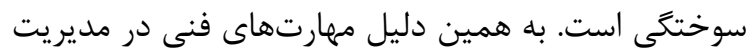
و تسكين درد در روند بهبودى بيماران سوختكى تأثير

بسزايى دارد [ه]].

معمولترين روش براى مقابله با درد استفاده از داز دارئ داروهاست كه در ابتدا در حيطهُ كار يرستارى قرار نمى دئيرد.

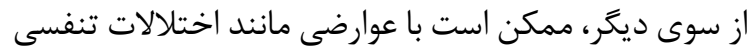

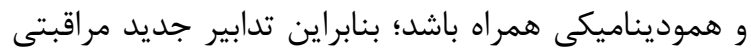
براى كاهش درد لازم است. همجنين در صورت تجويز دوز صحيح داروهاى مخدر، اين داروها به شيوه درست و مقدار

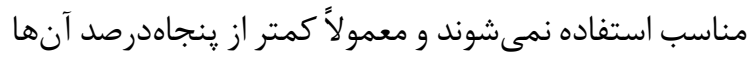
وارد بدن بيمار مىشود [ع, [V] طب مكمل يا طب جايكزين مجموعه اعمال و عقايدى است كه بيماران براى يِيشخيرى، درمان و ارتقاى سطح سلامتى و بهداشتى در كنار ساير درمانها استفاده مى كنند دئد

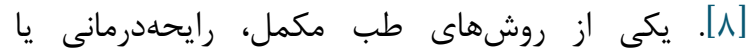

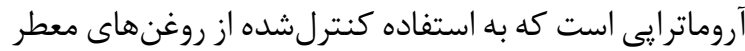

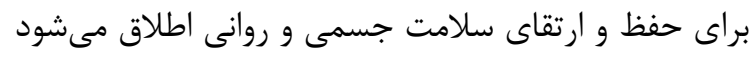

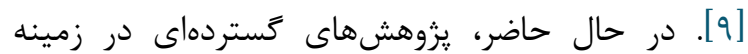
كاربردهاى گوناكون رايحهدرمانى و استفاده از اسانسهاى

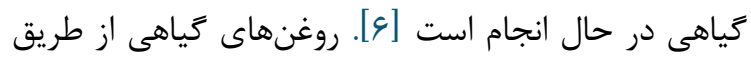

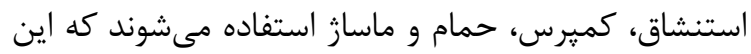

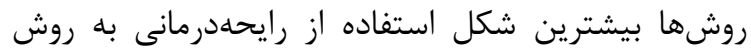

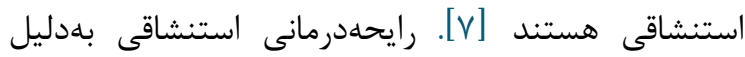
اثربخشى در كاهش اضطراب، درد، خستخى و بيمارىهاى يوستى كاربرد دارد [ • [1]. مكانيسم دقيق جَّونكى اثر گذارى رايحهدرمانى بهصورت

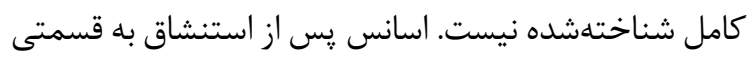

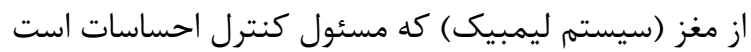

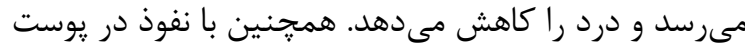

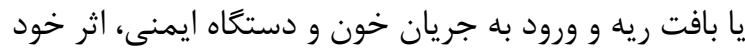

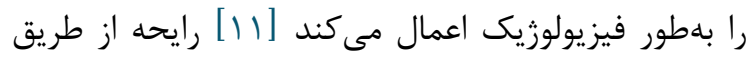
استنشاق وارد گردش خون مىشود و بلنظر مىرسد علاوهبر 
Scale) كه مقياسى خودَزارشى است استفاده شد. اين

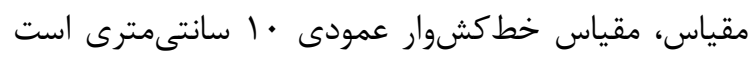

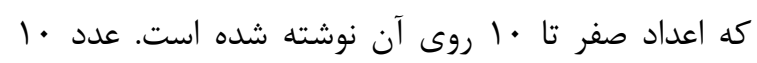

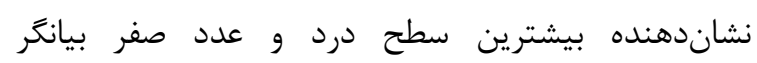

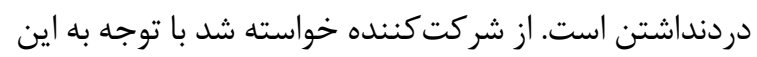

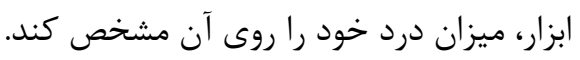

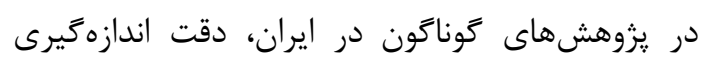

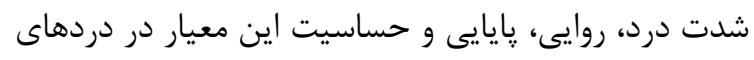

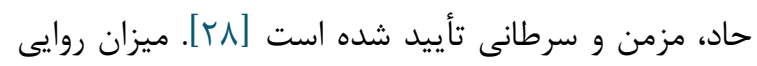

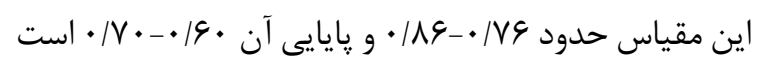

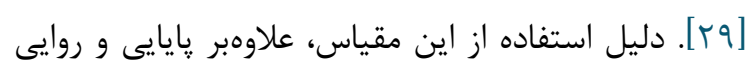

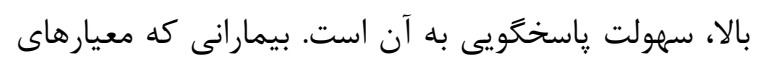

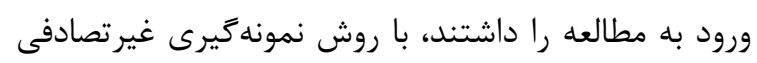

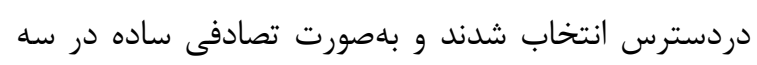

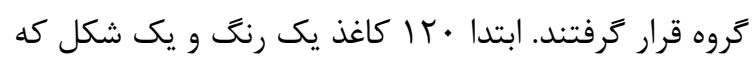

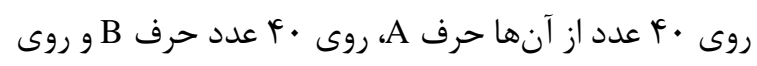

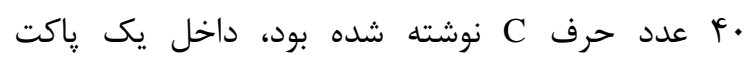

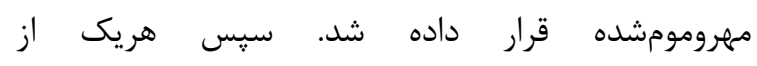

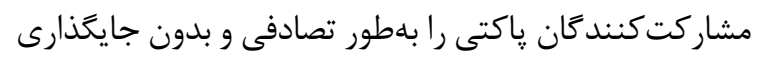

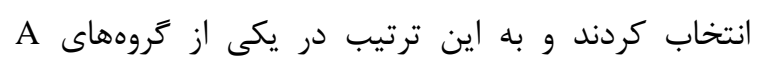
(اسطوخودوس)، B (يلاسبو) و C (كنترل) قرار كرفتند.

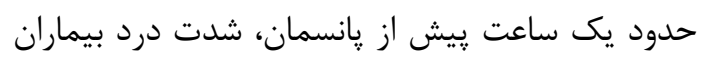

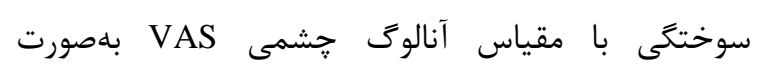
خودگزارشى و براى بيشخيرى از سوكيرى در ارزيابى اوليه

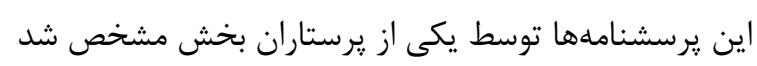

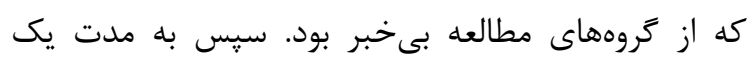

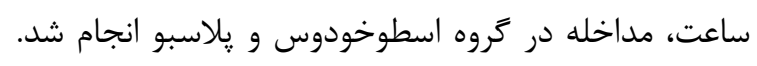

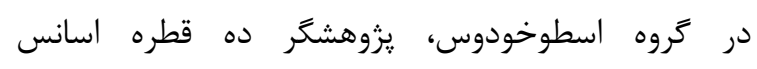
اسطوخودوس r درصد ساخت شركت باريج اسانس كاشان

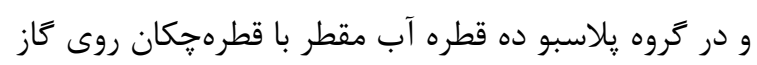

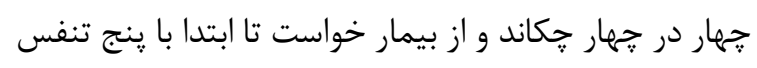

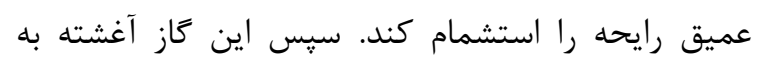

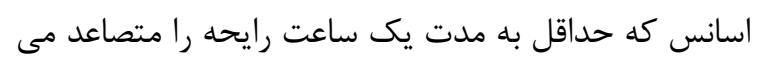

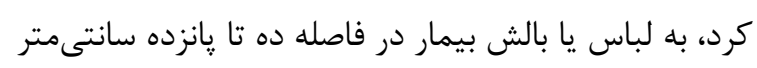

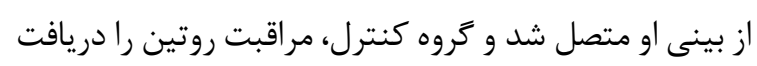

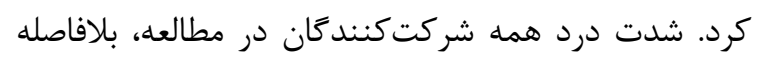

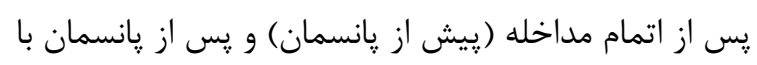

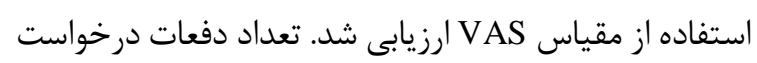

و شيوع قابلتوجه درد در بيماران سوختكى است [؟, צ؟].

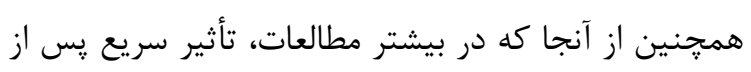

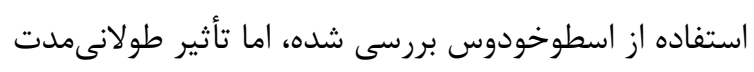

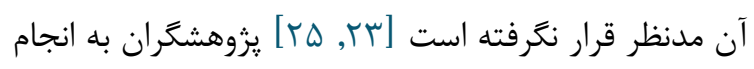

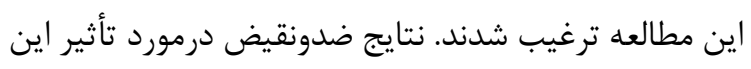

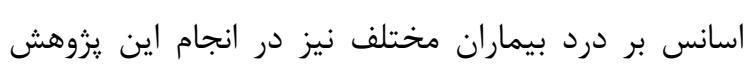

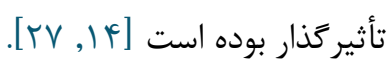

\section{روش بررسى}

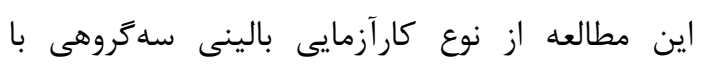

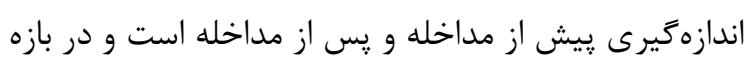

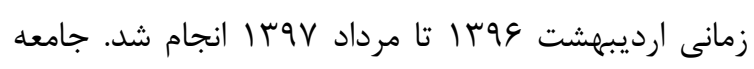

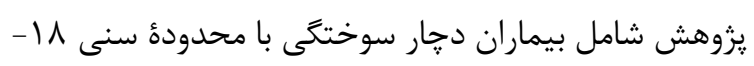

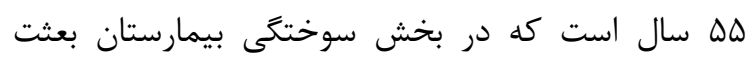

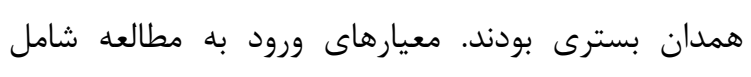

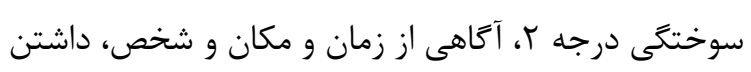

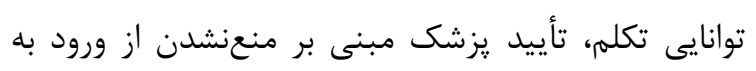

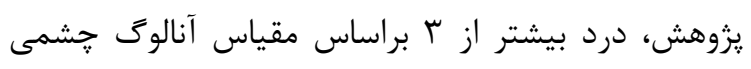
(Visual Analog Scale (VAS)) داروهاى كياهى، نداشتن اعتياد به مواد مخدر (بنا بر اظهار

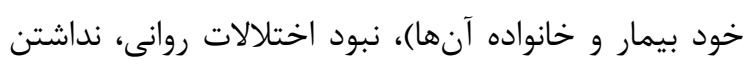

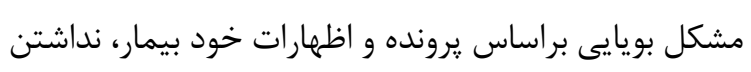

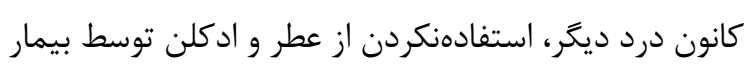

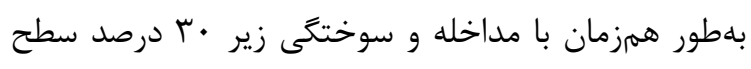
بدن براساس معيار لوند و برودر (Lond and Broder) است.

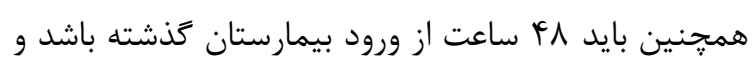
خودسوزى علت سوختتى نباشد. معيارهاى خروج از مطالعه نيز شامل مصرف داروهاى گياهى ديكر توسط بيمار، داشتن

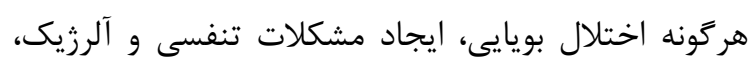

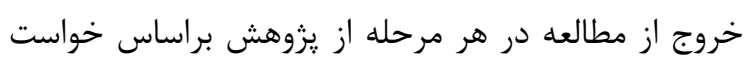

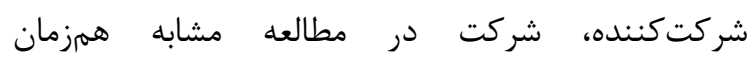

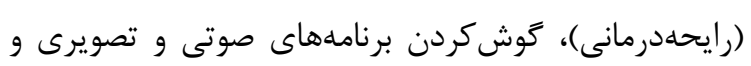
مصرف داروهاى ضد درد است. يرسشنامه مشخصات دموكرافيك شامل سن، مئ ديزان

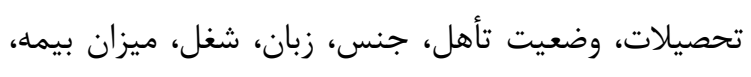

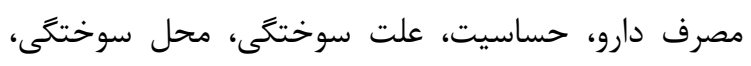

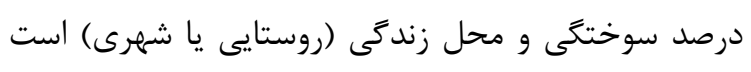

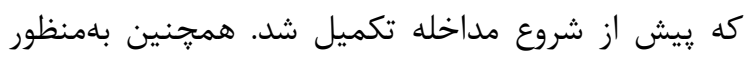

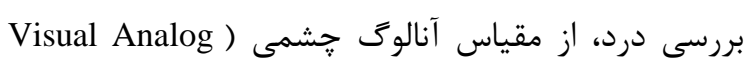




\section{• . F اثربخشى رايحهدرمانى استنشاقى با اسانس اسطوخودوس ....}

روشهاى آمار توصيفى و آزمونهاى آمارى اندازهخيرى

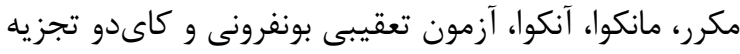

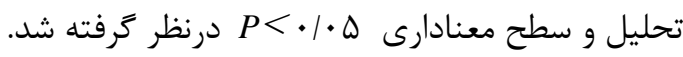

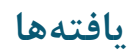

يس از اعمال معيارهاى ورود، • با بيمار وارد مطالعه شدند. در اين ميان از • ا نفر صرفنظر شد و درنهايت نفر در هر گروه مدنظر قرار كرفتند (نمودار ()).

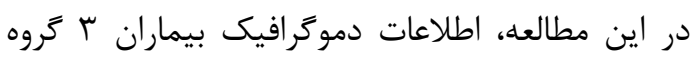
بررسى شد. نتايج نشان داد كه اين كروهها بهجز در متغير زبان مادرى، از نظر ساير متغيرهاى دموكرافيك هممسان

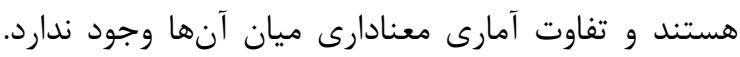
متغير درد نيز از توزيع نرمال برخوردار است (جدول ().
مسكن هريك از شركت كنندكان تا دوازده ساعت پِ از مداخله نيز مدنظر قرار كرفت.

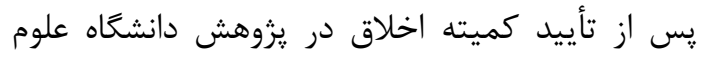

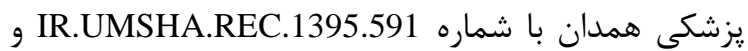
ثبت مطالعه در مركز كارآزمايى بالينى ايران به شماره

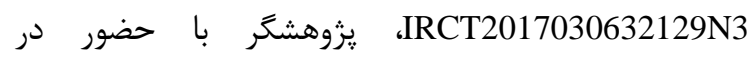
بيمارستان بعثت همدان و دريافت مجوز لازم از مدير خدمات

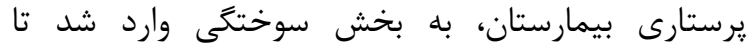
نمونه گيرى و مداخله را در بخش مورد نظر انجام دهد.

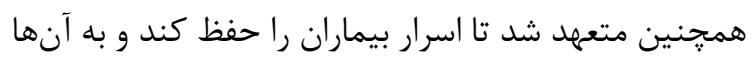
ضررى نرساند. پس از دريافت رضايت آكاهانه براى شركت

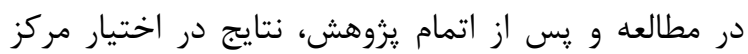
تحقيقات دانشكاه قرار ترفت. دادهاى مطالعه با توجه به اهداف مطالعه جمع آورى شد. همجنين با استفاده از نرمافزار آمارى SPSS نسخه آلا،

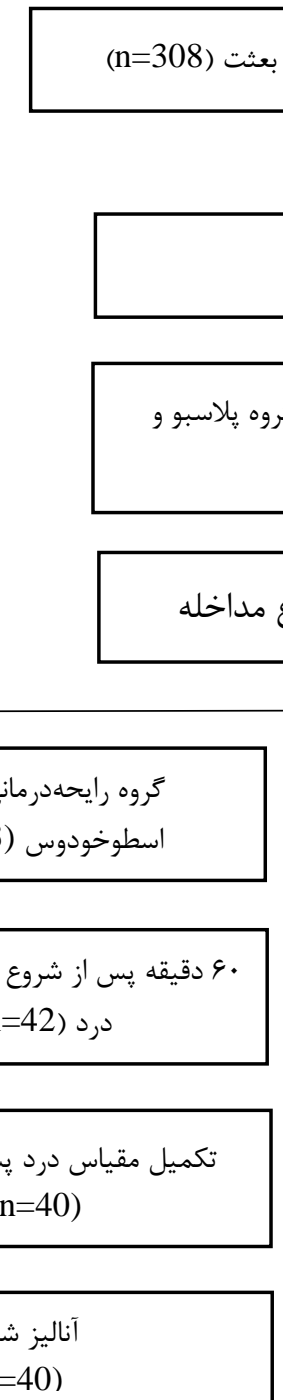

(n=130) ورود به مطالعه كنترل (n=130)

$$
\text { (n=130) كنرل) }
$$$$
\text { تكميل مقياس درد ييش از شرو }
$$

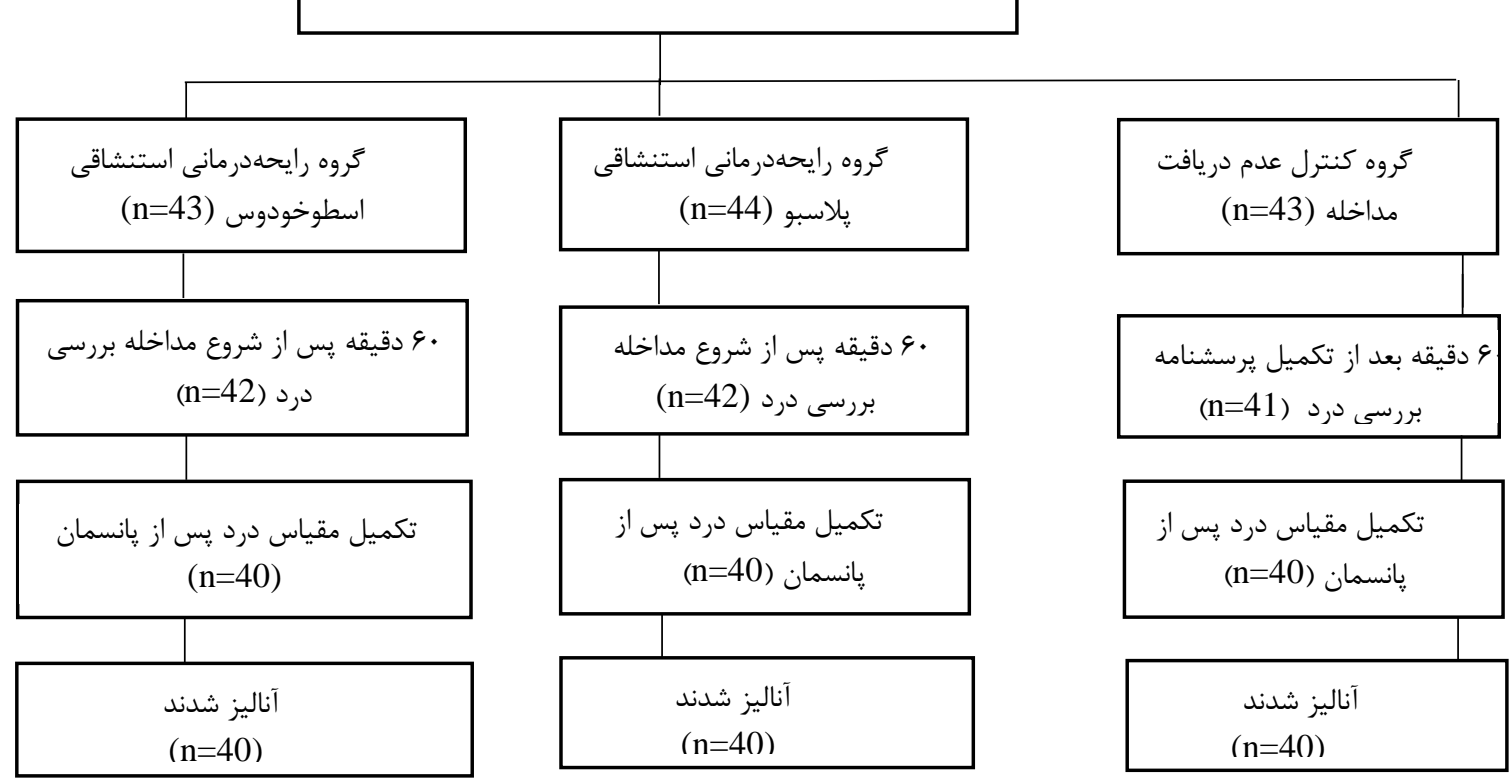

نمودار ا. كونسورت مطالعه

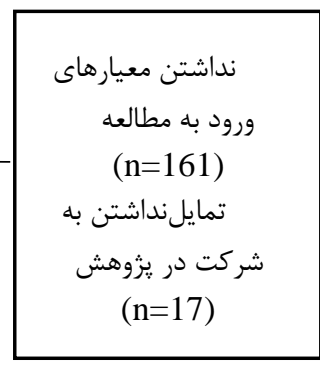

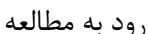

$(n=161)$

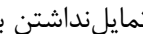

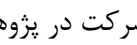
$(n=17)$

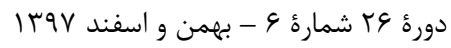


جدول ا. مقايسه متغيرهاى دموكر افيك در بيماران مبتلا به سوختكى برحسب گروه درمانى

\begin{tabular}{|c|c|c|c|c|c|}
\hline \multirow{2}{*}{ P Value } & & تروه درمانى & & \multirow[b]{2}{*}{ متغير } & \\
\hline & فراوانى (درصد) دروتين & فراوانى (درصد) & فراوانى (درصد) & & \\
\hline \multirow{2}{*}{$\cdot 19 \cdot \Delta$} & $(\Delta \cdot) \Gamma \cdot$ & $(F V / D) 19$ & $(q \Delta) \backslash \wedge$ & زن - ا & \multirow{2}{*}{ جنس } \\
\hline & $(\Delta \cdot) \Gamma \cdot$ & $(\Delta \Gamma / Q) \Gamma I$ & $(\Delta \Delta) Y T$ & مرد & \\
\hline . & 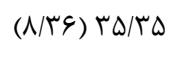 & $(\Lambda / \vee q) r V / r \Lambda$ & (१/r $)$ ( $) / ৭ \Lambda$ & سن & \multirow{4}{*}{ تأهل وضعيت } \\
\hline \multirow{3}{*}{ - /TMY } & $(I T / \Delta) \Delta$ & $(r \cdot) \wedge$ & $(I V / \Delta) \vee$ & مجرد & \\
\hline & $(\Lambda \vee / \Delta) r \Delta$ & $(V Y / Q) Y q$ & $(V V / \Delta) \Psi$ & متأهل & \\
\hline & $(\cdot) \cdot$ & $(V / Q) r$ & (b) $r$ & همسر مرده & \\
\hline \multirow{2}{*}{$\cdot \mid \cdot \Delta 1$} & rr & $(V \cdot / \cdot) \Gamma \Lambda$ & س & شهر & \multirow{2}{*}{ سكونت محل } \\
\hline & $(I V / \Delta) \vee$ & $(r \cdot / \cdot) \mid r$ & $(F T / Q) I V$ & روستا & \\
\hline \multirow{4}{*}{$\cdot / \cdot r$} & $(\Delta Y / \Delta) Y I$ & $(F \vee / Q) 19$ & $(\Delta Y / \Delta) Y I$ & فارس & \multirow{4}{*}{ 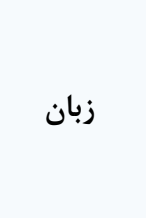 } \\
\hline & $(F Y / Q) \backslash V$ & $(Y V / D) \backslash 1$ & $(F T / D) I V$ & ترك & \\
\hline & $(r V / \Delta) \| 1$ & $(I r / \Delta) \Delta$ & $(T / \Delta) 1$ & لر & \\
\hline & $(V / D) \Psi$ & $(I T / \Delta) \Delta$ & $(\Gamma / \Delta) 1$ & 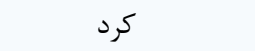 & \\
\hline \multirow{4}{*}{. I THt } & $(V / Q) \Gamma$ & $(V / Q) \Gamma$ & $(1 \cdot)^{f}$ & خواندن و نوشتن & \multirow{4}{*}{ تحصيلات } \\
\hline & $(\Delta T / \Delta) T^{\prime}$ & $(\Delta \cdot) r \cdot$ & $(F \Delta) \backslash \wedge$ & ديڤِم & \\
\hline & $(r \Delta))$. & Tr/D)וT & $(r \cdot) \| r$ & فوقدييلم و ليسانس & \\
\hline & $(r \cdot) \wedge$ & $(1 \cdot)^{F}$ & $(1 \Delta) \&$ & فوقليسانس و بالاتر & \\
\hline \multirow{3}{*}{$\cdot / T V \Delta$} & $(V \Delta)^{r} \cdot$ & r & $(V \cdot) \backslash \Lambda$ & $(\vee \Delta)^{r} \cdot$ & \multirow{3}{*}{ سوخيه } \\
\hline & $(\mid V / \Delta) \vee$ & $(I r / \Delta) \Delta$ & $(T \cdot) \wedge$ & $(\mid V / Q) \vee$ & \\
\hline & $(V / Q) Y$ & $(V / \Delta) r$ & $(1 \cdot)^{\mathrm{F}}$ & $(V / \Delta) \Gamma$ & \\
\hline \multirow{8}{*}{.$/ 1 F}$. & $(\Delta \Delta) Y T$ & ( & $(f \cdot) \mid 9$ & آب جوش & \multirow{8}{*}{ سوختخَى علت } \\
\hline & $(r / Q))$ & $(\cdot) \cdot$ & (b) $Y$ & نفت & \\
\hline & $(T V / D) \|$ & $(Y Y / Q) 9$ & $(T \Delta) 1$. & كاز & \\
\hline & $(I T / \Delta) \Delta$ & $(V / \Delta) r$ & $(V / \Delta) r$ & قير & \\
\hline & $(\cdot) \cdot$ & $(r / Q) 1$ & $(1 \cdot)^{f}$ & آتش & \\
\hline & $(\cdot) \cdot$ & $(\cdot) \cdot$ & $(\Gamma / \Delta) 1$ & روغن & \\
\hline & $(\Gamma / Q))$ & $(\cdot) \cdot$ & $(\cdot) \cdot$ & جسم داغ & \\
\hline & $(\cdot) \cdot$ & $(T / Q) 1$ & $(1 \cdot)^{c}$ & 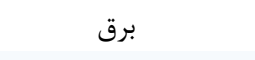 & \\
\hline \multirow{2}{*}{$1 / \cdots$} & $(1 \cdots) F$ & $(1 \cdots) f^{f}$. & $(1 \cdots) f \cdot$ & بلى ل & \multirow{2}{*}{ درمانى بيمه } \\
\hline & $(\cdot) \cdot$ & $(\cdot) \cdot$ & $(\cdot) \cdot$ & خير & \\
\hline \multirow{6}{*}{$\cdot \pi V V$} & $(T / Q))$ & $(\Delta) r$ & $(\Delta) r$ & كارمند & \multirow{6}{*}{ 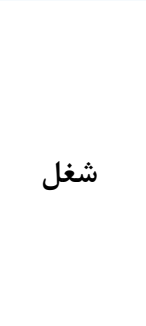 } \\
\hline & $(f \Delta) \backslash \Lambda$ & $(f \cdot) 19$ & $(r \Delta) \mid f$ & شغل آزاد & \\
\hline & $(\Gamma / \Delta) 1$ & $(V / Q) r$ & $(1 \cdot)^{F}$ & بازنشسته & \\
\hline & $(T / \Delta))$ & $(\cdot) \cdot$ & (b) $Y$ & بيكار & \\
\hline & $(F \vee / D) 19$ & $(F \vee / 0) 19$ & (rV/D) 10 & خانهدار & \\
\hline & $(\cdot) \cdot$ & $(\cdot) \cdot$ & $(V / \Delta) r$ & كشاورز & \\
\hline
\end{tabular}


Fr F اثربخشى رايحهدرمانى استنشاقى با اسانس اسطوخودوس ....

\begin{tabular}{|c|c|c|c|c|}
\hline \multirow{3}{*}{ P Value } & درمان روتين & يلاسبو & اسطوخودوس & \multirow{3}{*}{ متغير } \\
\hline & ميانكَين & ميانغَين (انحراف & ميانكَين & \\
\hline & (انحراف معيار) & معيار) & (انحراف معيار) & \\
\hline
\end{tabular}

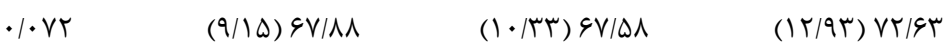

وزن

$\cdot 19 \cdot r$

$(V / 99) 199 / 44$

$(\Lambda / 99) \mid 9 V / 4 Y$

$(1 \cdot / 1 \cdot) 191 / 1$

قد

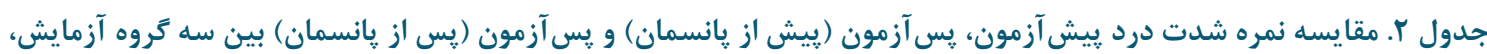

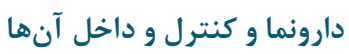

\begin{tabular}{|c|c|c|c|c|c|c|c|}
\hline \multirow{2}{*}{ آزمون } & \multicolumn{2}{|c|}{ كروه كنترل } & \multicolumn{2}{|c|}{ كروه دارونما } & \multicolumn{2}{|c|}{ تروه آزمون } & \multirow{2}{*}{ اندازهَّيرى درد } \\
\hline & انحراف معيار & ميانغين & انحراف معيار & ميانگين & انحراف معيار & ميانكين & \\
\hline $\begin{array}{l}\mathrm{F}=\cdot 1 \cdot 1 \mathrm{~V} \\
P=. / 9 \wedge \mathrm{r}\end{array}$ & .191 & $V / l$. & $1 / 1$. & $V / .9$ &.$/ 9 F$ & V/Ir & بيش از مداخله \\
\hline $\begin{array}{l}\mathrm{F}=99 / 9 \wedge \mathrm{V} \\
P=\cdot / \cdots\end{array}$ & - $/ v \Delta$ & $V / \cdot r$ & $1 / .4$ & $8 / 99$ & .19. & Q/IT & 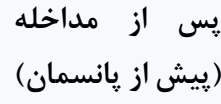 \\
\hline \multirow[t]{2}{*}{$\begin{array}{l}\mathrm{F}=1 / 944 \\
P=\cdot / 191\end{array}$} & $.19 \mathrm{~V}$ & $V / \cdot F^{4}$ & $1 / 19$ & $V / . r$ & $1 / 4$. & $9 / 94^{\circ}$ & 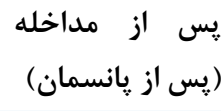 \\
\hline & \multicolumn{2}{|c|}{$\begin{array}{l}\mathrm{F}=\cdot / \wedge 9 \\
P=\cdot / 1 \cdot \wedge\end{array}$} & \multicolumn{2}{|c|}{$\begin{array}{l}\mathrm{F}=\cdot / \Lambda \mu \wedge \\
P=\cdot \mid q \Delta r\end{array}$} & \multicolumn{2}{|c|}{$\begin{array}{l}\mathrm{F}=\cdot|q| \varphi \\
P=\cdot \mid \cdot \ldots\end{array}$} & آزمون \\
\hline
\end{tabular}

ميان آنها متفاوت است؛ بهطورىكه پِيش از مداخله

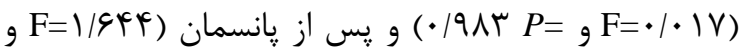

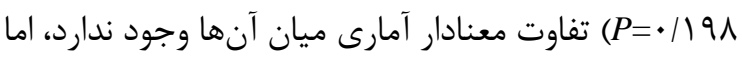

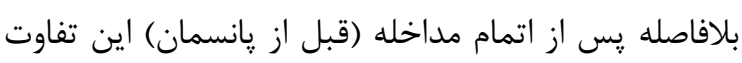

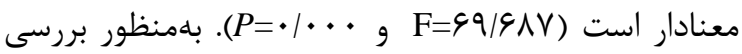

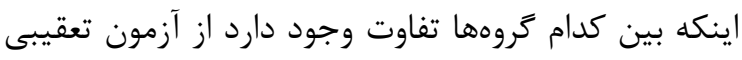
بونفرونى استفاده شد.
با توجه به جدول r و نتايج آناليز اندازهاى مكرر، بين

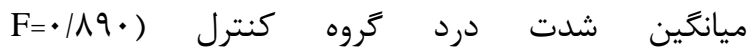

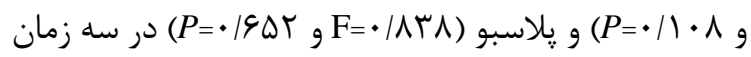

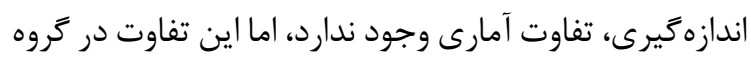

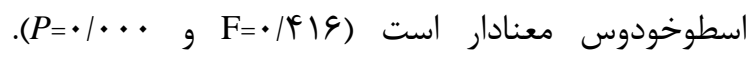

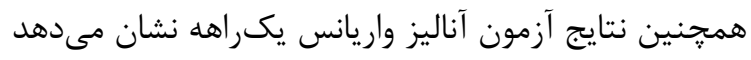

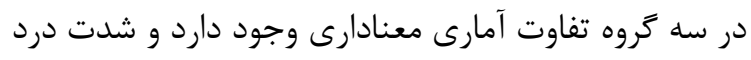
جدول ب. مقايسه تفاوت ميانغَين شدت درد در مرحله يس إز مداخله (بيش از يانسمان) بين تروههاى اسطوخودوس، يلاسبو و كنترل

\begin{tabular}{|c|c|c|c|}
\hline P Value & اختلاف ميانًَين & كروه & كروه \\
\hline$\cdot 1 \cdot$ & $-1 / 19$ & ليلاسبو & \multirow{2}{*}{ سطوخودوس } \\
\hline 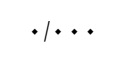 & $-1 / 19$ & كنترل & \\
\hline . 1914 &.$- / . r$ & كنترل & يلاسبو \\
\hline
\end{tabular}


Fr ب برسى مقايسهاى تأثير دو روش آموزش تركيبى و سخنرانى....

بلمنظور بررسى رابطه رايحهدرمانى با اسانس

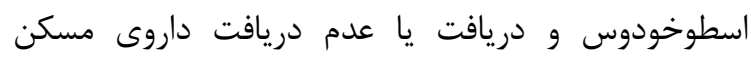

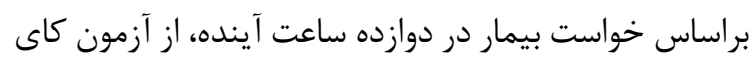

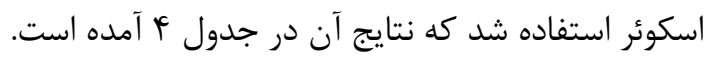

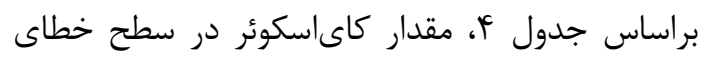

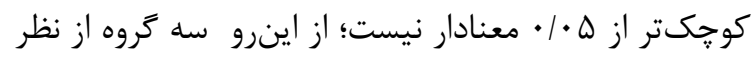

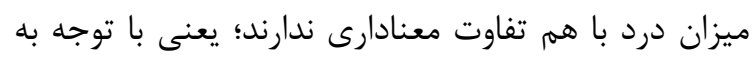

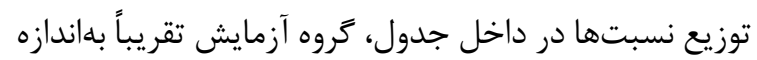

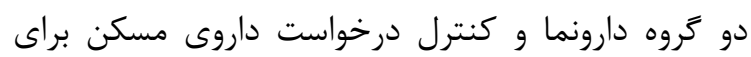

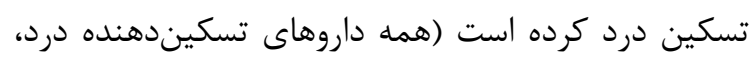

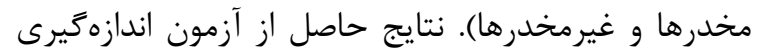

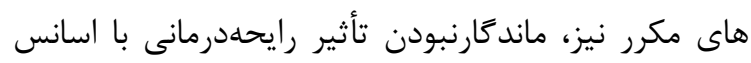
اسطوخودوس را تأييد مى كند.
مطابق جدول rا، نتايج آزمون تعقيبى توكى نشان

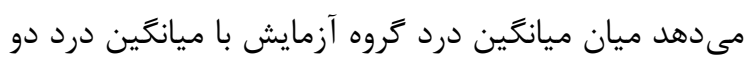

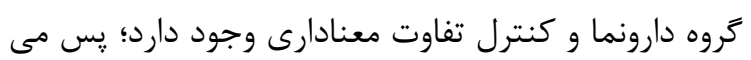
توان كفت رايحهدرمانى با عصاره اسطوخودوس سبب كارون كاهش

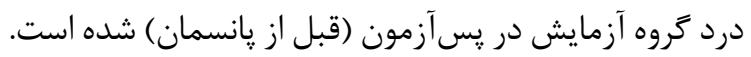

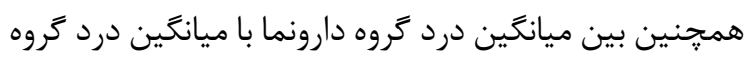
كنترل تفاوت معنادارى وجود ندارد. با توجه به شكل ا، ميانكين درد كروه آزمايش در

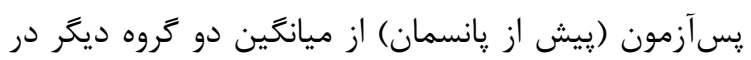

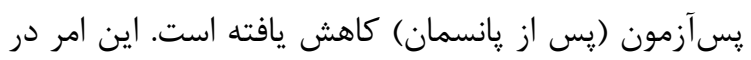

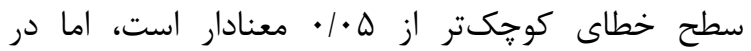

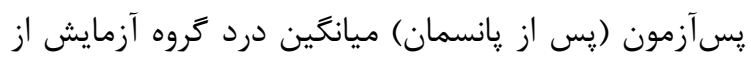

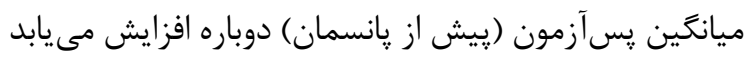

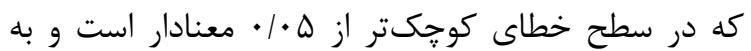

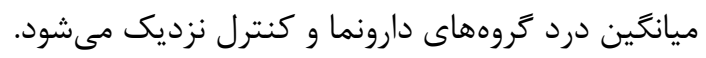
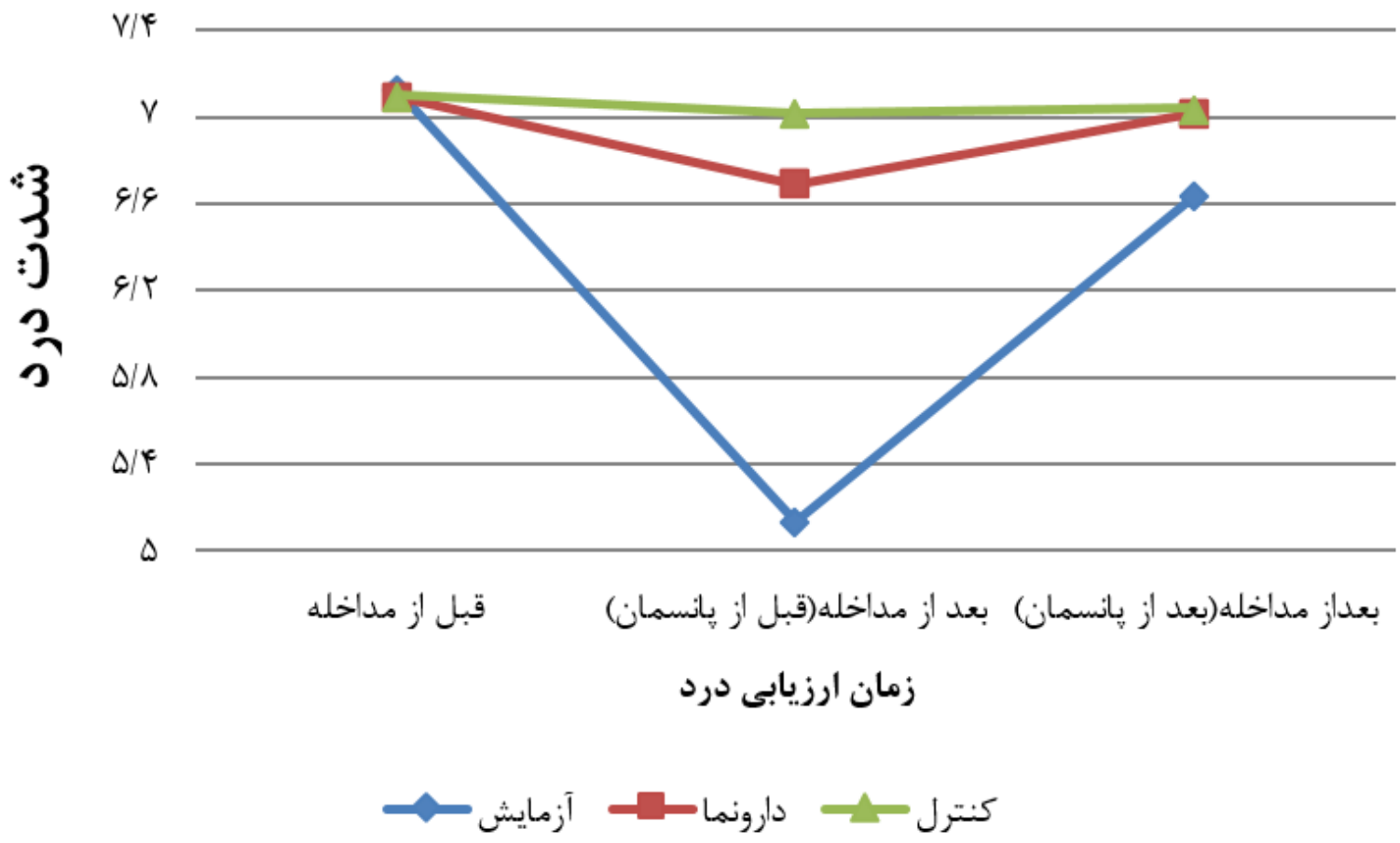

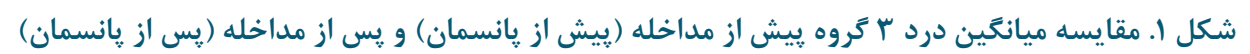


جدول F. دريافت داروهاى مسكن در دوازده ساعت اول يس از يانسمان در گروههاى مطالعه

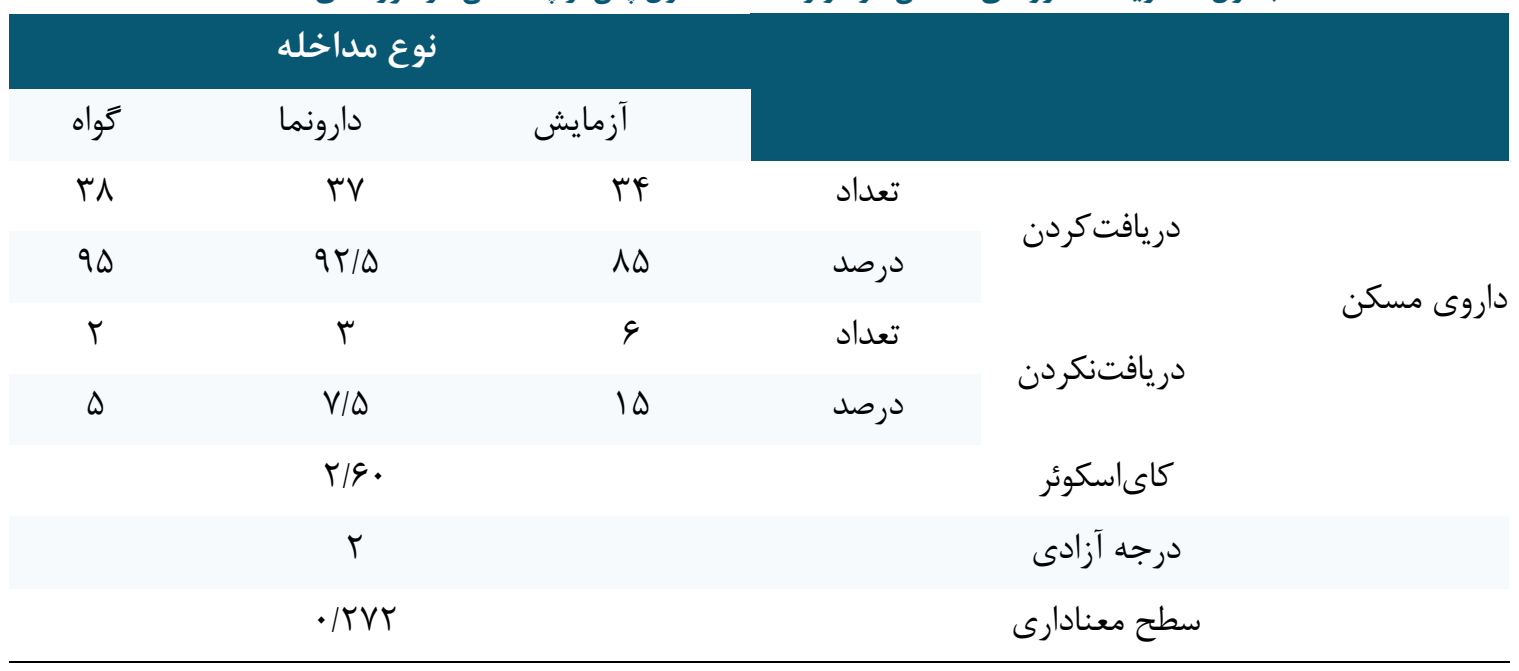

درد يس از عمل كروه آزمايش مىشود. با توجه به اثر

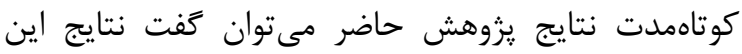

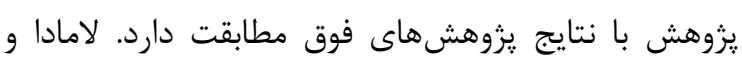

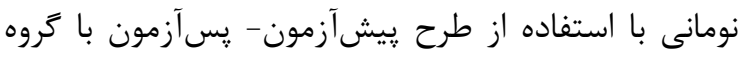

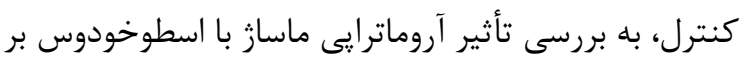

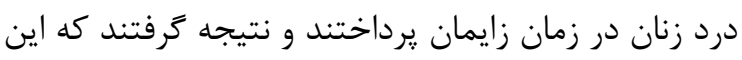

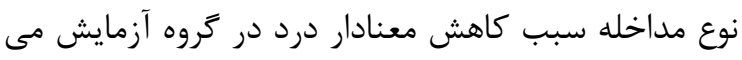
شود [بr].

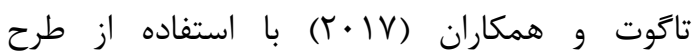

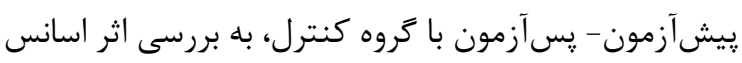

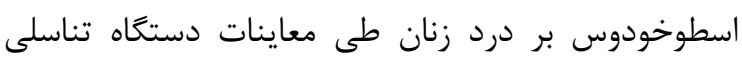

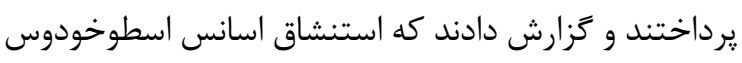

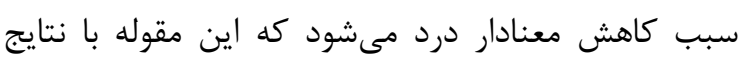

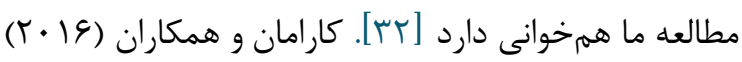

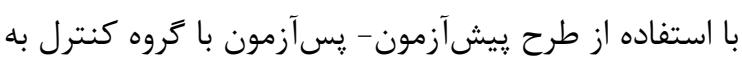

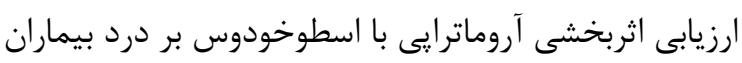

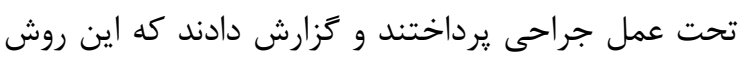

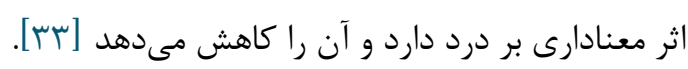

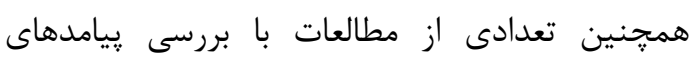

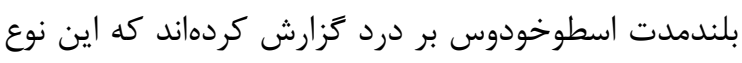

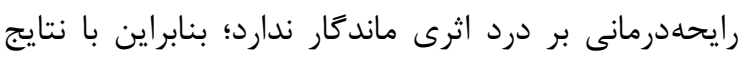

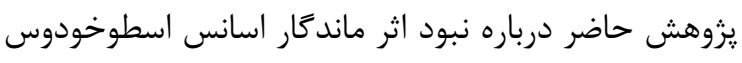

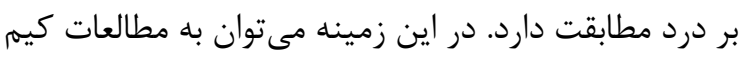

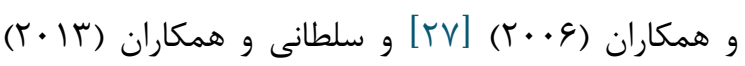

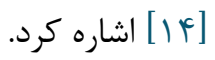

\section{بحث}

نتايج نشان مىدهد استنشاق اسانس اسطوخودوس

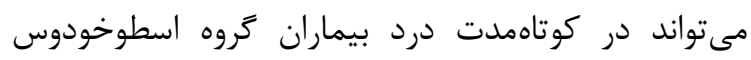

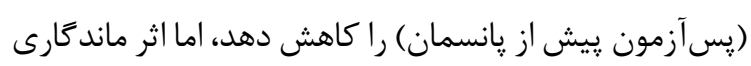

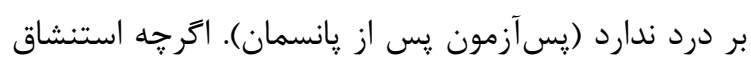

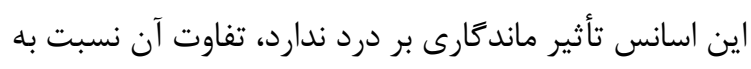

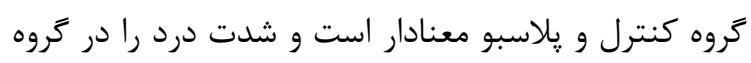
آزمايش كاهش داده است. در بيشتر يزوهشها، بدون توجه به آثار بلندمدت آنا اسانس

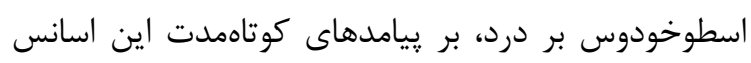

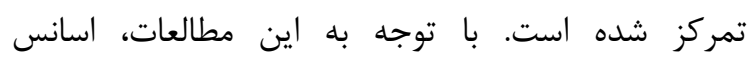

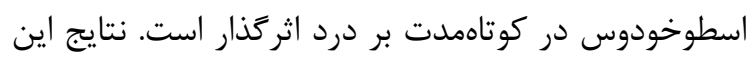

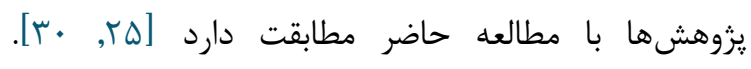

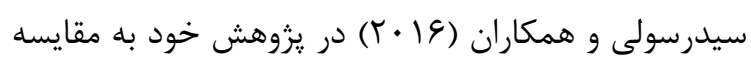

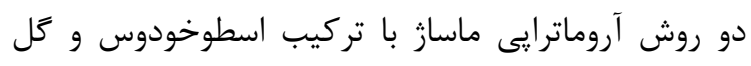

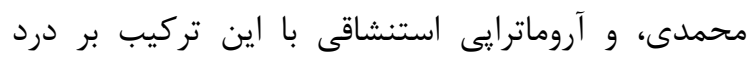

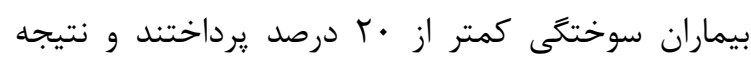

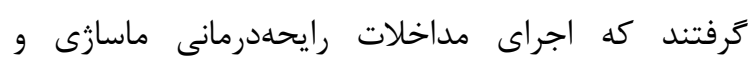

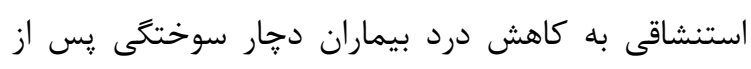
مداخله منجر مىشود. در مطالعه حاضر نيز، درد بلاف بلافاصله

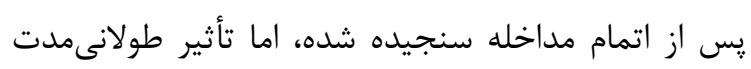

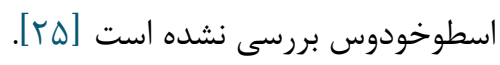

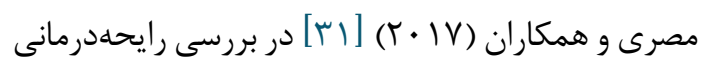
با اسانس اسطوخودوس بر درد بيماران در اتاق عمل نتيجه كرفتند كه رايحهدرمانى با اين اسانس، سبب كاهش مبرد معنادار 
زمان اول، بيمار نكران انجام يانسمان بود. در زمان دوم نيز

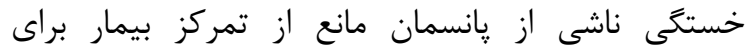

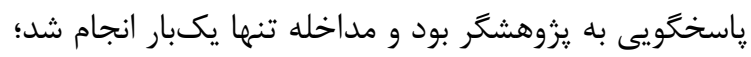

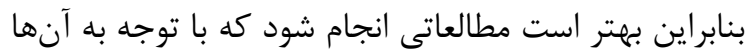

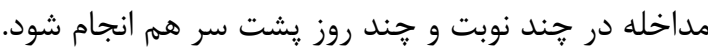

$$
\text { نتيجه كيرى }
$$

اجراى مداخله رايحهدرمانى استنشاقى با اسانس اسطوخودوس، به كاهش درد بيماران دجار سوختگى بعد از

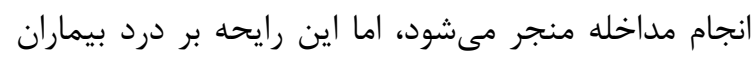
سوختكى اثرى كوتاهمدت دارد؛ بنابراين با توجه به نتايج

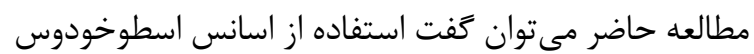
براى كاهش موقت و كوتاهمدت بيماران اولويت دارد، اما توصيه مىشود براى كاهش طولانىمدت درد از ساير روشهاى مؤثر استفاده شود.

$$
\text { سياسگز ارى }
$$

يروهشگران از مسئولان دانشگاه علوميزشكى و يرستاران

$$
\text { و ارزيابان و بيماران كمال تشكر را دارند. }
$$

$$
\text { تعارض در منافع }
$$

بين نويسندَان هيجَّونه تعارضى در منافع وجود ندارد.
سلطانى و همكاران (r| • r) نيز به بررسى تأثير اسانس

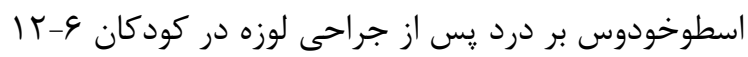

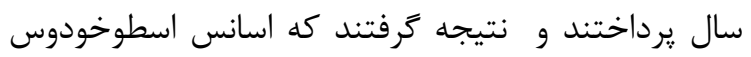

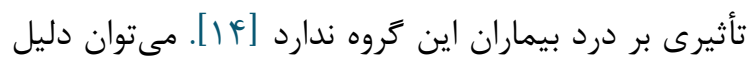
اين امر را تفاوت در وضعيت بيماران، نوع عمل و سن بيمار برار

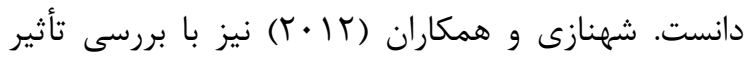
آروماترايى بر درد ناشى از جاگذارى آ.يو.دى در زنان نتيجه

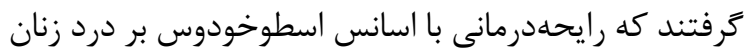

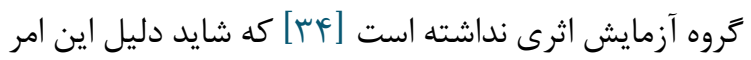

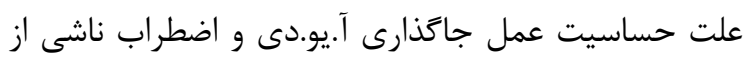
آن باشد. - ان

از سوى ديخر، مطالعات ديخرى وجود دارد كه با مطالعه

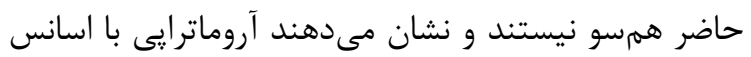

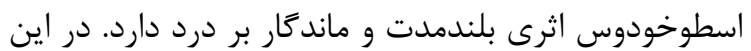

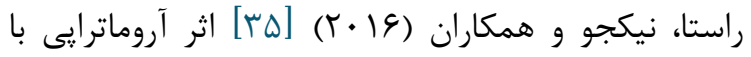
اسطوخودوس را بر شدت درد زنان در زمان ديسمنوره اوليه

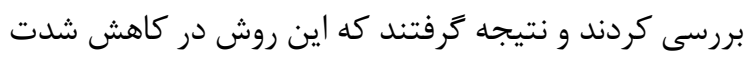

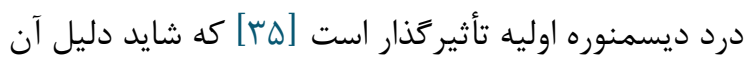
تفاوت در مشكل بيماران، مدت مداخله و تأثير ساير عوامل و متغيرهاى محيطى بر آن باشد.

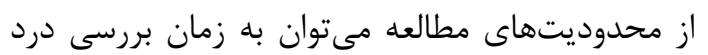

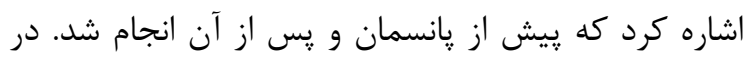

\section{References}

1. Burning Research Center of Iran University of Medical Sciences. Burning in Iran Tehran: Iran University of Medical Sciences; 2015 .

2. Ministry of Health and Medical Education (Iran). Statistics burn in Iran Tehran2016.

3. Apay SE, Arslan S, Akpinar RB, Celebioglu A. Effect of aromatherapy massage on dysmenorrhea in Turkish students. Pain management nursing. 2012 Dec 1;13(4):236-40. https://doi.org/10.1016/j.pmn.2010.04.002

4. Rhiner M, Palos G, Termini M. Managing breakthrough pain: a clinical review with three case studies using oral transmucosal fentanyl citrate. Clinical journal of oncology nursing. 2004;8(5).

https://doi.org/10.1188/04.CJON.507-512
5. Fonseca AD, Reis SS, Silva SM, Amaro FÉ, de Oliveira Neta AI, et al. Nursing care in burn patients. Unimontes Científica. 2017 Nov 9:14654.

6. Kanani M, Mazloum SR, Emami A, Mokhber N. The effect of aromatherapy with orange essential oils on anxiety in patients undergoing hemodialysis.

7. Bahraini S, Naji A, Mannani R. Effects of aromatherapy and its application. Journal of Urmia Nursing And Midwifery Faculty. 2011 Apr 15;9(1): 1-8.

8. Montazeri A, Sajadian A, Ebrahimi M, Haghighat S, Harirchi I. Factors predicting the use of complementary and alternative therapies among cancer patients in Iran. European journal of cancer care. $2007 \quad$ Mar;16(2):144-9. https://doi.org/10.1111/j.1365-2354.2006.00722.x 
9. Mashouf S, Aflaki M, Zanjani SE, Mojab F. The Effects of Aromatherapy by Lavender Oil on Agitation and Hemodynamic Parameters in Mechanically Ventilated Patients in ICU. Traditional and Integrative Medicine. 2017 Sep 24:119-28.

10. O'Flaherty LA, van Dijk M, Albertyn R, Millar A, Rode H. Aromatherapy massage seems to enhance relaxation in children with burns: an observational pilot study. Burns. 2012 Sep 1;38(6):840-5. https://doi.org/10.1016/j.burns.2012.01.007

11. Rizvi A, Mishra A, Mahdi AA, Ahmad M, Basit A. Natural and herbal stress remedies: a review. International Journal of Pharmacognosy. 2015;2(4):155-60.

12. Lindquist R, Tracy MF, Snyder M, editors. Complementary \& alternative therapies in nursing. Springer Publishing Company; 2018 Mar 28. https://doi.org/10.1891/9780826144348

13. Lakhan SE, Sheafer H, Tepper D. The effectiveness of aromatherapy in reducing pain: a systematic review and meta-analysis. Pain research and treatment. 2016;2016.

14. Soltani R, Soheilipour S, Hajhashemi V, Asghari G, Bagheri M, Molavi M. Evaluation of the effect of aromatherapy with lavender essential oil on post-tonsillectomy pain in pediatric patients: a randomized controlled trial. International journal of pediatric otorhinolaryngology. 2013 Sep 1;77(9):1579-81. https://doi.org/10.1016/j.ijporl.2013.07.014

15. Thomas DV. Aromatherapy: mythical, magical, or medicinal?. Holistic Nursing Practice. 2002 Oct 1;17(1):8-16. https://doi.org/10.1097/00004650$\underline{\text { 200210000-00005 }}$

16. Najafi Z, Taghadosi M, Sharifi K, Farrokhian A, Tagharrobi Z. The effects of inhalation aromatherapy on anxiety in patients with myocardial infarction: a randomized clinical trial. Iranian Red Crescent Medical Journal. 2014 Aug;16(8): e15485. https://doi.org/10.5812/ircmj.15485

17. Candan F, Unlu M, Tepe B, Daferera D, Polissiou M, Sökmen A, Akpulat HA. Antioxidant and antimicrobial activity of the essential oil and methanol extracts of Achillea millefolium subsp. millefolium Afan.(Asteraceae). Journal of ethnopharmacology. 2003 Aug 1;87(2-3):215-20. https://doi.org/10.1016/S0378-8741(03)00149-1

18. Atsumi T, Tonosaki K. Smelling lavender and rosemary increases free radical scavenging activity and decreases cortisol level in saliva. Psychiatry Research. $2007 \quad$ Feb 28;150(1):89-96. https://doi.org/10.1016/j.psychres.2005.12.012
FF اثربخشى رايحهدرمانى استنشاقى با اسانس اسطوخودوس ....

19. Yayla EM, Ozdemir L. Effect of Inhalation Aromatherapy on Procedural Pain and Anxiety After Needle Insertion Into an Implantable Central Venous Port Catheter: A Quasi-Randomized Controlled Pilot Study. Cancer nursing. 2019;42(1):35-41.

20. Vakilian K, Atarha M, Bekhradi R, Chaman R. Healing advantages of lavender essential oil during episiotomy recovery: a clinical trial. Complementary therapies in clinical practice. 2011 Feb $1 ; 17(1): 50-3$ https://doi.org/10.1016/j.ctcp.2010.05.006

21. Sheikhan F, Jahdi F, Khoei EM, Shamsalizadeh N, Sheikhan M, Haghani H. Episiotomy pain relief: Use of Lavender oil essence in primiparous Iranian women. Complementary therapies in clinical practice. 2012 Feb 1;18(1):66-70. https://doi.org/10.1016/j.ctcp.2011.02.003

22. Pirak A, Salehian T, Yazdkhasti M, Didehvar M, Arzani A. The effect of lavender essence on labor pain and length of delivery time in nulliparous women.

23. Lamadah SM, Nomani I. The effect of aromatherapy massage using lavender oil on the level of pain and anxiety during labour among primigravida women. Am J Nurs Sci. 2016;5(2):37-44. https://doi.org/10.11648/j.ajns.20160502.11

24. Janula Raju MS. Effectiveness of aromatherapy in reducing labour pain and duration of labour among primigravidas: a pilot study. International Journal of Health Sciences and Research (IJHSR). 2014; 4 (2): 124-8.

25. Seyyed-Rasooli A, Salehi F, Mohammadpoorasl A, Goljaryan S, Seyyedi Z, Thomson B. Comparing the effects of aromatherapy massage and inhalation aromatherapy on anxiety and pain in burn patients: A single-blind randomized clinical trial. Burns. 2016 Dec 1;42(8):1774-80 https://doi.org/10.1016/i.burns.2016.06.014

26. Öster C, Kildal M, Ekselius L. Return to work after burn injury: burn-injured individuals' perception of barriers and facilitators. Journal of Burn Care \& Research. $2010 \quad$ Jul 1;31(4):540-50. https://doi.org/10.1097/BCR.0b013e3181e4d692

27. Kim JT, Wajda M, Cuff G, Serota D, Schlame M, Axelrod DM, Guth AA, Bekker AY. Evaluation of aromatherapy in treating postoperative pain: pilot study. Pain Practice. 2006 Dec;6(4):273-7. https://doi.org/10.1111/j.1533-2500.2006.00095.x

28. Dehghani K, Dehghani H, Najari Z. Effect of Subcutaneous Enoxaparin Injection Duration on Site-Pain Intensity in Acute Coronary Syndrome Patients Hospitalized in CCU Afshar Hospital, Yazd, 2011. 
29. Boonstra AM, Preuper HR, Reneman MF, Posthumus JB, Stewart RE. Reliability and validity of the visual analogue scale for disability in patients with chronic musculoskeletal pain. International journal of rehabilitation research. 2008 Jun 1;31(2):165-9. https://doi.org/10.1097/MRR.0b013e3282fc0f93

30. Bikmoradi A, Harorani M, Roshanaei G, Moradkhani S, Falahinia GH. The effect of inhalation aromatherapy with damask rose (Rosa damascena) essence on the pain intensity after dressing in patients with burns: A clinical randomized trial. Iranian journal of nursing and midwifery research. 2016 May;21(3):247. https://doi.org/10.4103/1735-9066.180380

31. Mesri M. Effect of lavender aromatherapy on anxiety and hemodynamic changes: A randomized clinical trial. Quarterly Qom University Of Medical Sciences Journal. 2017; 10 (12): 69-76.

32. Tugut N, Demirel G, Baser M, Ata EE, Karakus S. Effects of lavender scent on patients' anxiety and pain levels during gynecological examination. Complementary therapies in clinical practice. 2017 Aug;28:65.

https://doi.org/10.1016/j.ctcp.2017.05.006
33. Karaman T, Karaman S, Dogru S, Tapar H, Sahin A, Suren M, et al. Evaluating the efficacy of lavender aromatherapy on peripheral venous cannulation pain and anxiety: A prospective, randomized study. Complementary therapies in clinical practice. 2016 May 1;23:64-8. https://doi.org/10.1016/j.ctcp.2016.03.008

34. Shahnazi M, Nikjoo R, Yavarikia P, MohammadAlizadeh-Charandabi S. Inhaled lavender effect on anxiety and pain caused from intrauterine device insertion. Journal of caring sciences. 2012 Dec;1(4):255.

35. Nikjou R, Kazemzadeh R, Rostamnegad M, Moshfegi S, Karimollahi M, Salehi H. The effect of lavender aromatherapy on the pain severity of primary dysmenorrhea: A triple-blind randomized clinical trial. Annals of medical and health sciences research. 2016;6(4):211-5 https://doi.org/10.4103/amhsr.amhsr_527_14 